\title{
VLDL Cholesterol Subtype 3 Measurement
}

National Cancer Institute

\section{Source}

National Cancer Institute. VLDL Cholesterol Subtype 3 Measurement. NCI Thesaurus.

Code C120669.

The determination of the very low density lipoprotein cholesterol subtype 3 present in a sample. 